\title{
Cytotoxicity of fractured quartz on THP-1 human macrophages: role of the membranolytic activity of quartz and phagolysosome destabilization
}

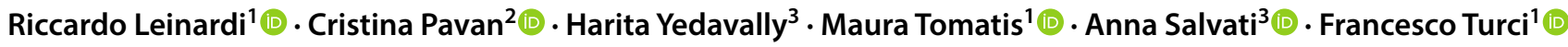

Received: 7 April 2020 / Accepted: 18 June 2020 / Published online: 26 June 2020

(c) The Author(s) 2020

\begin{abstract}
The pathogenicity of quartz involves lysosomal alteration in alveolar macrophages. This event triggers the inflammatory cascade that may lead to quartz-induced silicosis and eventually lung cancer. Experiments with synthetic quartz crystals recently showed that quartz dust is cytotoxic only when the atomic order of the crystal surfaces is upset by fracturing. Cytotoxicity was not observed when quartz had as-grown, unfractured surfaces. These findings raised questions on the potential impact of quartz surfaces on the phagolysosomal membrane upon internalization of the particles by macrophages. To gain insights on the surface-induced cytotoxicity of quartz, as-grown and fractured quartz particles in respirable size differing only in surface properties related to fracturing were prepared and physico-chemically characterized. Synthetic quartz particles were compared to a well-known toxic commercial quartz dust. Membranolysis was assessed on red blood cells, and quartz uptake, cell viability and effects on lysosomes were assessed on human PMA-differentiated THP-1 macrophages, upon exposing cells to increasing concentrations of quartz particles $(10-250 \mu \mathrm{g} / \mathrm{ml})$. All quartz samples were internalized, but only fractured quartz elicited cytotoxicity and phagolysosomal alterations. These effects were blunted when uptake was suppressed by incubating macrophages with particles at $4{ }^{\circ} \mathrm{C}$. Membranolysis, but not cytotoxicity, was quenched when fractured quartz was incubated with cells in protein-supplemented medium. We propose that, upon internalization, the phagolysosome environment rapidly removes serum proteins from the quartz surface, restoring quartz membranolytic activity in the phagolysosomes. Our findings indicate that the cytotoxic activity of fractured quartz is elicited by promoting phagolysosomal membrane alteration.
\end{abstract}

Keywords Quartz cytotoxicity · Quartz surface · Macrophages $\cdot$ Membrane $\cdot$ Phagolysosome

\section{Abbreviations}

AM Alveolar macrophages

AOP Adverse outcome pathway

Anna Salvati

a.salvati@rug.nl

$\triangle$ Francesco Turci

francesco.turci@unito.it

1 "G. Scansetti” Interdepartmental Center for Studies On Asbestos and Other Toxic Particulates, Department of Chemistry, University of Torino, Via P. Giuria 7, 10125 Turin, Italy

2 Louvain Centre for Toxicology and Applied Pharmacology (LTAP), Université Catholique de Louvain, Avenue Hippocrate 57, 1200 Brussels, Belgium

3 Department of Nanomedicine \& Drug Targeting, Groningen Research Institute of Pharmacy (GRIP), University of Groningen, Antonius Deusinglaan 1, Groningen 9713 AV, The Netherlands

$\begin{array}{ll}\text { BET } & \text { Brunauer-Emmett-Teller } \\ \text { cRPMI } & \text { Complete RPMI (RPMI + 10\% FBS) } \\ \text { DLS } & \text { Dynamic light scattering } \\ \text { ELS } & \text { Electronic light scattering } \\ \text { FBS } & \text { Fetal bovine serum } \\ \text { FPIA } & \text { Flow particle image analyser } \\ \text { LMP } & \text { Lysosome membrane permeabilization } \\ \text { MIE } & \text { Molecular initiating event } \\ \text { MTT } & \text { 3-(4,5-Dimethylthiazol-2-yl)-2,5-diphenyltetra- } \\ & \text { zolium bromide } \\ \text { PFA } & \text { Paraformaldehyde } \\ \text { PI } & \text { Propidium iodide } \\ \text { PMA } & \text { Phorbol myristyl acetate } \\ \text { RCS } & \text { Respirable crystalline silica } \\ \text { RPMI } & \text { Rosewell Park Memorial Institute 1640 Medium } \\ \text { SEM } & \text { Scanning electron microscopy } \\ \text { SSA } & \text { Specific surface area } \\ \text { TEM } & \text { Transmission electron microscopy }\end{array}$




\section{Introduction}

Exposure to crystalline silica dusts, in particular quartz, induces severe toxic effects in humans (American Thoracic Society 1997; Parks et al. 1999; Leung et al. 2009; IARC 2012). It is also known that a cluster of dust properties, including particle size (Wiessner et al. 1989; Fenoglio et al. 2000), the capacity to induce free radicals (Vallyathan et al. 1988; Dalal et al. 1990; Schins et al. 2002), and the degree of hydrophilicity, related to the distribution of siloxanes and silanol families on the particle surface (Bolis et al. 1991; Hemenway et al. 1994), give a contribution to the adverse effects of quartz in vitro and in vivo. The various adverse cellular effects reported in the literature are related to particle-membrane interactions (Warheit et al. 2007), and to the activation of lung cells (Shen et al. 2001; Gilberti et al. 2008; Giordano et al. 2010). Recently, a revisited mechanism of toxicity for quartz particles in the alveolar space has been proposed (Pavan and Fubini 2017). According to this model, inhaled particles are recognized and internalized by alveolar macrophages to be cleared out from the lungs (Hamilton et al. 2008). The deposition of non-cleared particles onto the alveolar epithelium causes the recruitment and the activation of new macrophages and neutrophils, in a self-sustained detrimental process which gives rise to persistent inflammation, as long as the particles remain in the alveolar space.

The alveolar macrophages (AM) are among the first cells of the body to have significant contact with inhaled particles (Hamilton et al. 2008; Hiraiwa and Van Eeden 2013). Because of the active phagocytosis of AM, quartz particles mainly interact with the macrophage phagolysosomal membrane (Joshi et al. 2015). It is, in fact, known that most particles accumulate at lysosomal level following uptake, and because of this, the particle impact on the phagolysosomes is a key parameter to be investigated (Rejman et al. 2004; Nel et al. 2009; Salvati et al. 2011; Wang et al. 2013; Sabella et al. 2014). Upon quartz phagocytosis, lysosome membrane permeabilization (LMP) may occur and, the lysosomal content, such as cathepsins B and S (Wang et al. 2013; Hughes et al. 2015), may leak into the cytosol. As recently evidenced, this event can trigger the NALP3 inflammasome machinery (Hughes et al. 2015; Sayan and Mossman 2015), which in turn causes activation of the proteolytic enzyme caspase- 1 and the release of active pro-inflammatory cytokines (i.e. IL-1 $\beta$ and IL-18) (Pavan et al. 2014; Rabolli et al. 2015; Hindman and Ma 2019). The interaction of quartz particles with the phagolysosomal membrane, a crucial step according to the model of quartz-induced inflammogenicity, was recently proposed as the molecular initiating event (MIE) of the quartz adverse outcome pathway (AOP) towards persistent inflammation and silicosis (Pavan and Fubini 2017). In search for the molecular determinant of this interaction, a considerable number of works have been published in the last few years (Pavan et al. 2013, 2014, 2017; Turci et al. 2016; Joshi et al. 2017). Traditionally, a well-established biomembrane model is represented by the red blood cell (Nolan et al. 1981), and hemolysis is largely used to probe the interaction of amorphous and crystalline silica particles with biomembranes (Gerashchenko et al. 2002; Zhao et al. 2011; Pavan et al. 2013). Recently, we have demonstrated that synthetic quartz crystals are hemolytic only upon mechanical fracturing, a procedure that upsets the expected long-range order of quartz non-radical surface moieties (such as silanols, silanolates, siloxanes) (Turci et al. 2016). In previous studies, several approaches were developed to modulate cellular responses to quartz by modifying its surface in many different ways (Daniel et al. 1995; Duffin et al. 2001; Fubini and Hubbard 2003). However, a clear connection between the surface states and features of different quartz particles and their impact on cellular membranes, and more particularly the phagolysosomal membrane, still needs to be established.

Here, we investigated the impact of quartz particles on human macrophages, specifically analyzing whether quartz can induce alterations of the phagolysosome membrane. To this aim, we compared the effect on cell viability and impact at the lysosomal level of three surface-differentiated quartz specimens, namely: an ad-hoc synthesized quartz crystal in respirable size (Pastero et al. 2016), exposing as-grown, unfractured, regular faces; a synthetic quartz mechanically fractured down to a size similar to the as-grown quartz; and a cytotoxic commercial quartz dust used in several toxicological works, as a positive control (Allison 1966; Castranova 2004; Lison et al. 2009; Pfau et al. 2012). Human red blood cells were used as a model of the cellular membrane (not capable of internalization) for assessing quartz membranolytic activity and for evidencing the effect of protein adsorption on the membranolytic activity of fractured quartz. PMA-differentiated THP-1 cells were selected as a common model for human alveolar macrophages (Theus et al. 2004; Wottrich et al. 2004; Kletting et al. 2018). Particle uptake was monitored by transmission electron microscopy (TEM) and a combination of cell viability and flow cytometrybased assays was used to determine alterations induced at lysosomal level. This work provides novel and fundamental insights on the mechanisms of the pathogenicity of quartz, clarifying the nature of the molecular initiating event resulting from the interaction of quartz crystals with the phagolysosomes, following particle internalization by macrophages. 


\section{Materials and methods}

\section{Crystalline silica samples}

Two synthetic $\alpha$-quartz samples with as-grown (gQ) or fractured (gQ-f) faces were used in this study. A commercial fractured $\alpha$-quartz dust, largely used in studies of experimental silicosis and lung cancer (Min-U-Sil 5 quartz, US Silica Co., Berkeley Springs, WV, USA, lot number 15062696, in this work named cQ-f), was used as positive control.

Synthetic quartz crystals with as-grown regular faces (gQ) were obtained following the procedure developed by Pastero and coworkers (Pastero et al. 2016). Briefly, a 25\% w/w Na-metasilicate (Na-MTS) solution was polymerized into gel by the addition of $1 \mathrm{M} \mathrm{HNO}_{3}$. The gel was stabilized at $\mathrm{pH} \approx 8$. Growth runs were performed in polytetrafluoroethylene (PTFE) liner steel autoclaves at $210{ }^{\circ} \mathrm{C}$, for $168 \mathrm{~h}$. The finest fraction $(<30 \mu \mathrm{m})$, obtained through $30 \mathrm{~min}$ of sieving in 100 and $30 \mu \mathrm{m}$ sieves, was used in all the experiments. To obtain crystals with fractured faces (gQ-f), a further synthesis was carried out, where the Na-MTS solution was polymerized by bubbling $\mathrm{CO}_{2}$ until gel formation, at $\mathrm{pH}$ ca. 8. By growing quartz with $\mathrm{CO}_{2}$ as polymerizing agent, we synthesized large crystals that could be conveniently ground in a ball mill, obtaining fractured crystals with size and specific surface area well comparable to gQ crystals. The largest fraction ( $>30 \mu \mathrm{m})$, obtained as above, was mechanically fractured by milling in a MM 200 mixer mill (Retsch, Haan, Germany) in agate jars $(27 \mathrm{~Hz}$, two spheres, $500 \mathrm{mg}$ of dust/jar) for $6 \mathrm{~h}$, to induce surface alterations. Thus, following this procedure, we were able to obtain asgrown (gQ) and fractured (gQ-f) crystals, that shared very similar physicochemical properties (particle size distribution, chemical composition, surface area, surface charge at physiological $\mathrm{pH}$ ) and only differed in the occurrence of surface structures induced by fracturing.

\section{Particle size distribution}

Particle size distribution was determined by Flow Particles Image Analyzer (FPIA), using a Sysmex FPIA 3000 particle size and shape analyser (Malvern Panalytical, Malvern, UK) and by dynamic light scattering (DLS), using a Zetasizer Nano ZS (Malvern Instruments, Malvern, UK). For FPIA analysis, a sample dispersion of $0.5 \mathrm{mg} / \mathrm{ml}$ in Milli-Q water was prepared and probe sonicated on ice for $3 \mathrm{~min}$ at $30 \%$ amplitude, power $25 \mathrm{~W}$, energy delivered into the sample $0.450 \mathrm{~kJ} / \mathrm{ml}$, using a Sonopuls HD3100 homogeniser (Bandelin, Berlin, Germany). For DLS analysis, a sample dispersion in Roswell Park Memorial Institute (RPMI) 1640 medium $(0.5 \mathrm{mg} / \mathrm{ml})$, with the addition of $10 \%$ foetal bovine serum (FBS), was prepared and sonicated as described.

\section{Surface area determination}

Specific surface area (SSA) was evaluated by the Brunauer-Emmett-Teller (BET) method, based on $\mathrm{Kr}$ adsorption. Quartz samples were firstly outgassed for $2 \mathrm{~h}$, at $150{ }^{\circ} \mathrm{C}$. The analysis was then performed at $-196{ }^{\circ} \mathrm{C}$ using an ASAP 2020 physisorption analyser (Micromeritics, Norcross, USA).

\section{乙-Potential}

The $\zeta$ potential of the quartz samples was evaluated by means of electrophoretic light scattering (ELS) with a Zetasizer Nano-ZS (Malvern-Panalytical, Malvern, UK). In this technique, the velocity of a particle in an oscillating electric field, which is proportional to its $\zeta$ potential, is measured by light scattering. The $\zeta$ potential was measured after suspending quartz $(0.5 \mathrm{mg} / \mathrm{ml})$ in serum-free RPMI medium (s.f. RPMI) or RPMI + 10\% FBS (complete RPMI medium, cRPMI), to evaluate the surface charge at exposure conditions ( $\mathrm{pH} \mathrm{ca} .8$ ) and the modulation given by serum proteins. Investigation of zeta potential at lysosomal $\mathrm{pH}(\mathrm{pH} 4.5)$ was measured suspending quartz particles $(0.5 \mathrm{mg} / \mathrm{ml})$ in $0.01 \mathrm{M}$ $\mathrm{NaCl}$, and adjusting the $\mathrm{pH}$ of the suspension to the experimental value with $0.1 \mathrm{M} \mathrm{HCl}$ or $0.1 \mathrm{M} \mathrm{NaOH}$.

\section{Cell culture and differentiation}

RPMI medium, FBS and Dulbecco's phosphate-buffered saline (DPBS) were purchased from Gibco (Thermo Fischer Scientific, Waltham, MA, USA). Experiments were performed on human THP-1, a human monocyte-like cell line derived from a patient with leukaemia, obtained from ATCC bank (ATCC\#TIB-202, RRID: CVCL_0006) (Tsuchiya et al. 1980). Cells suspensions were cultured in RPMI 1640 supplemented with $10 \%$ FBS (cRPMI), at $37^{\circ} \mathrm{C}$ and $5 \% \mathrm{CO}_{2}$. After seeding (200,000 or 100,000 cells/well in a Cellstar 24-well plate for LysoTracker staining and propidium iodide (PI) staining, respectively, or 50,000 cells/ well in a Cellstar transparent 96-well plate for MTT assay), cells were differentiated into macrophages by incubation with $100 \mathrm{nM}$ phorbol 12-myristate 13-acetate (PMA) in cell culture medium for $48 \mathrm{~h}$ at $37{ }^{\circ} \mathrm{C}$ and $5 \% \mathrm{CO}_{2}$ (Tsuchiya et al. 1982). Transparent 24-well and 96-well plates were purchased from Greiner Bio-One (Greiner Bio-One, Kremsmunster, Austria).

\section{TEM imaging}

Particle uptake by THP-1 macrophages was investigated by means of transmission electron microscopy on cross 
sections of fixed cells, upon $24 \mathrm{~h}$ incubation with $50 \mu \mathrm{g} /$ $\mathrm{ml}$ of synthetic or commercial quartz samples. After exposure, the cells were fixed with $0.2 \%$ glutaraldehyde and $2 \%$ paraformaldehyde (PFA) in $0.1 \mathrm{M}$ sodium cacodylate buffer ( $\mathrm{pH}$ 7.4) for $1 \mathrm{~h}$. Then, cells were rinsed twice for $5 \mathrm{~min}$ in $0.1 \mathrm{M}$ cacodylate buffer at room temperature followed by post-fixation in $1 \%$ osmium tetroxide $1.5 \%$ potassium ferrocyanide in $0.1 \mathrm{M}$ sodium cacodylate at $4{ }^{\circ} \mathrm{C}$ for $30 \mathrm{~min}$. The cells were then washed with Milli-Q water, dehydrated through serial incubation in a graded ethanol series (30, 50, 70 and 100\%), and lastly embedded in EPON resin and polymerized at $37^{\circ} \mathrm{C}$ for $16 \mathrm{~h}$ followed by $58^{\circ} \mathrm{C}$ for $24 \mathrm{~h}$. Given the size of the particles and the fact that they are hard to cut with a standard diamond knife, sections were cut at a thickness of $200 \mathrm{~nm}$ instead of the standard $80 \mathrm{~nm}$ using an UC7 ultramicrotome (Leica, Vienna, Austria). This allowed to partially reduce the presence of holes in the section, corresponding to areas were particles accumulate and that cannot be sectioned, while still being able to determine whether particle uptake was present. Sections were then contrasted using 5\% uranyl acetate for $20 \mathrm{~min}$, followed by Reynolds lead citrate for $2 \mathrm{~min}$. Images were recorded with a CM100 Biotwin transmission electron microscope (FEI, Eindhoven, the Netherlands) operated at $80 \mathrm{kV}$ using a Morada digital camera.

\section{MTT assay}

Cell metabolic activity was assessed through a 3-(4,5-dimethylthiazol-2-yl)-2,5-diphenyltetrazolium bromide (MTT) assay (Gerlier and Thomasset 1986). After differentiation, THP-1 macrophages, previously plated at a density of 50,000 cells/ well in a transparent 96-well plate, were exposed for $24 \mathrm{~h}$ to quartz particles at increasing concentrations (10, 25, 50, 100, $250 \mu \mathrm{g} / \mathrm{ml}$ ) in complete medium (cRPMI). Before the assay, each well was washed with Dulbecco's Phosphate-Buffered Saline (DPBS) to remove the extracellular particles and eventual cell debris and treated with MTT $(0.5 \mathrm{mg} / \mathrm{ml})$ in cRPMI for $20 \mathrm{~min}$ at $37^{\circ} \mathrm{C}$. Then, the MTT reagent was discarded and dimethyl sulfoxide (DMSO) was added to each well (200 $\mu \mathrm{l})$ to solubilise formazan crystals. Each well was pipetted again to mix, and absorbance at $550 \mathrm{~nm}$ was measured using a THERMOmax microplate reader (Molecular Devices, San Josè, CA, USA). All values were normalized to the results obtained in untreated cells.

MTT assay was also carried out after $4 \mathrm{~h}$ of exposure at $4{ }^{\circ} \mathrm{C}$, to block active cellular processes (Dunn et al. 1980; Sharma et al. 2010). Plates with cells were pre-incubated at $4{ }^{\circ} \mathrm{C}$ for $30 \mathrm{~min}$, just before the exposure to quartz particles $(25,50,100,250 \mu \mathrm{g} / \mathrm{ml})$ in cRPMI. After $4 \mathrm{~h}$ of incubation, wells were washed three times with cRPMI $(100 \mu \mathrm{l})$, and further incubated in fresh medium without particles for $20 \mathrm{~h}$ at $37{ }^{\circ} \mathrm{C}$ and $5 \% \mathrm{CO}_{2}$. The same protocol was applied for 4-h exposure at $37^{\circ} \mathrm{C}$. To assess protein modulation on quartz cytotoxicity, the MTT assay was carried out as previously explained, exposing PMA-differentiated THP-1 cells (50,000 cells/well) for 4 or $24 \mathrm{~h}$ to quartz samples $(100 \mu \mathrm{g} /$ $\mathrm{ml}$ ), in s.f. RPMI or cRPMI supplemented with $10 \%$ FBS. The analysis was carried out as described above. MTT results are the mean of four biological replicates of one representative experiment out of three.

\section{Lyso Tracker staining and flow cytometry (FACS)}

The impact on the lysosomes after interaction and internalization of particles was investigated by staining cells with Lyso Tracker Red DND-99 (Thermo Fisher Scientific, Waltham, MA, USA), a fluorescent acidotropic probe for labelling and tracking acidic organelles in live cells. Increase in Lyso Tracker intensity from the basal condition can be due to an increase in lysosomal volume, lysosomal number, or lysosomal acidity. THP-1 cells differentiated into macrophages were exposed to particle dispersions $(25,50,100 \mu \mathrm{g} / \mathrm{ml})$ prepared by diluting a stock dispersion $(1 \mathrm{mg} / \mathrm{ml})$ in cRPMI. Cells were grown on transparent 24-well plates (200,000 cells/well), differentiated for $48 \mathrm{~h}$ as described above, and then exposed to particles. After $24 \mathrm{~h}$ exposure, at $37^{\circ} \mathrm{C}$ and $5 \% \mathrm{CO}_{2}$, wells were washed $(1 \times 500 \mu \mathrm{l}$ with the complete medium) to remove quartz particles, then cells were incubated $15 \mathrm{~min}$ at $37{ }^{\circ} \mathrm{C}, 5 \% \mathrm{CO}_{2}$, with a solution $(25 \mathrm{nmol}, 500 \mu \mathrm{l})$ of Lyso Tracker Red DND-99 (Thermo Fisher Scientific, Waltham, MA, USA), in cRPMI. Then, the dye solution was discarded and wells were washed again with cRPMI $(1 \times 500 \mu \mathrm{l})$ and DPBS $(2 \times 500 \mu \mathrm{l})$. Cells were detached with $0.05 \%$ trypsin/EDTA $(300 \mu \mathrm{l})$ at $37^{\circ} \mathrm{C}$ for $5 \mathrm{~min}$, followed by treatment with EDTA solution $(5 \mathrm{mmol})$ in PBS (pH 7.4), at $37{ }^{\circ} \mathrm{C}$. Then, cells were harvested in FACS tubes and pelleted by centrifugation at $250 \mathrm{~g}$ for $3 \mathrm{~min}$. Cells were resuspended in DPBS $(100 \mu \mathrm{l})$ and analysed using a CytoFlex flow cytometer (Beckman-Coulter, Brea, CA, USA). LysoTracker Red fluorescence intensity was analyzed in the FL3 channel. Quantitative analysis of flow cytometry data was carried out using the FlowJo software (TreeStar Inc., Ashland, OR, USA). Gates were set to discriminate cell debris and cell doublets from the analysis, according to their forward and side scattering. 20,000 cells were acquired, unless specified in the case of samples for which strong cytotoxicity was detected (in these cases a variable number of cells, ranging from 20,000 to at least ca. 7000 was acquired, as specified in figure captions). The same experiment was performed after $4 \mathrm{~h}$ exposure at 4 and $37{ }^{\circ} \mathrm{C}$, for cells exposed to 50 and $100 \mu \mathrm{g} / \mathrm{ml}$ of particles. The exposure at $4{ }^{\circ} \mathrm{C}$ was preceded by a $30-\mathrm{min}$ pre-incubation step of cells, at the same temperature.

The shown Lyso Tracker Red data are the result of three biological replicates of one representative experiment out of three. 


\section{Propidium iodide (PI) assay}

THP- 1 cells differentiated into macrophages were seeded on transparent 24 -well plates $(100,000$ cells/well) and, $48 \mathrm{~h}$ after seeding, cells were exposed to particles (final concentration: $100 \mu \mathrm{g} / \mathrm{ml}$ ) in serum-free (- FBS) or complete RPMI (+FBS). After $4 \mathrm{~h}$ exposure at $37^{\circ} \mathrm{C}$ and $5 \% \mathrm{CO}_{2}$, quartz dispersions were discarded and wells were washed with cRPMI $(1 \times 500 \mu \mathrm{l})$. Then, cells were harvested as described, collected into FACS tubes and stained with a PI solution $(5 \mu \mathrm{g} / \mathrm{ml})$ at room temperature. After incubation with the dye $\left(15 \mathrm{~min}, 37^{\circ} \mathrm{C}\right)$, samples were measured as described above. A variable number of cells, ranging from 12,000 to ca. 7000, were acquired for each sample (as specified in the figure caption). PI assay data result from one representative experiment out of three, using four replicates. Data were analyzed using the FlowJo software (Tree Star Inc., Ashland, OR, USA).

\section{Hemolysis assay}

The hemolytic activity of quartz particles refers to a method described by Lu \& coworkers (Lu et al. 2009), with minor modifications given by Pavan \& coworkers (Pavan et al. 2013). Red blood cells (RBCs) were separated from fresh human blood of healthy volunteer donors, not receiving any pharmacological treatment. To assess the effect of FBS proteins on quartz hemolytic activity, particles were incubated with increasing concentrations of FBS $(0.03 \%, 0.06 \%, 0.3 \%)$ in the exposure medium (DPBS). Briefly, quartz suspensions $(75 \mu \mathrm{l} / \mathrm{well}$,) at a concentration of $0.37 \mathrm{mg} / \mathrm{ml}$ were dispensed in a transparent 96-well Cellstar microplate (Greiner Bio-One, Kremsmunster, Austria), and FBS (75 $\mu 1 /$ well) was added, to each well. After $30 \mathrm{~min}$ of incubation at room temperature $\left(25^{\circ} \mathrm{C}\right)$, the red blood cell suspension $(75 \mu \mathrm{l} /$ well) was added, and the plate, gently shaken on an orbital plate shaker, was incubated for $30 \mathrm{~min}$ at $25^{\circ} \mathrm{C}$.

The plate was centrifuged for 5 min at $1200 \mathrm{RPM}$, using a Centrifuge Rotina 420R centrifuge (Hettic Instruments, Beverly, MA, USA). The supernatant ( $75 \mu \mathrm{l})$ was removed and transferred to a clean transparent microplate. The amount of haemoglobin released into the supernatant was spectrophotometrically determined at a wavelength of $540 \mathrm{~nm}$ with an Infinite $200 \mathrm{UV} / \mathrm{Vis}$ spectrophotometer (Tecan, Grödig, Austria). Absorbance values were converted into percentages of haemolysis according to the formula (Eq. 1):
DPBS and $0.1 \%$ Triton-X100 were used as negative and positive controls, respectively. Released hemoglobyn did not adsorb on quartz samples (data not shown).

\section{Statistical analysis}

Statistical analysis was performed using Systat 10 (Systat Software Inc., San Jose, CA, USA), and carried out by one-way analysis of variance (ANOVA) followed by Tukey's post hoc test, as appropriate. Differences with $p$ value $<0.05$ were considered statistically significant.

\section{Results}

\section{As-grown and fractured crystals share similar physico-chemical properties}

To study the impact of quartz particles on phagolysosome membrane, two synthetic quartz samples, with as-grown regular $(\mathrm{gQ})$ or fractured (gQ-f) surfaces were prepared, from a similar synthesis (Pastero et al. 2016). A commercial quartz dust (cQ-f) was used as a positive control, due to its known ability to induce cytotoxicity, increase in lysosomal permeability, and inflammogenic activity (Thibodeau et al. 2004; Dostert et al. 2008; Hornung et al. 2008; Sellamuthu 2011). Overall, physico-chemical characterization results showed that samples share both particle size distribution and, albeit to a lesser extent, surface charge, under the test conditions (Table 1).

Dimensional characterization showed that the samples had a respirable micrometric size. Field-emission scanning electron microscopy (FE-SEM) analysis confirmed that as-grown gQ crystals had a well-organized morphology, with flat and smooth surfaces. Fractured gQ-f and cQ-f exhibited a morphology typical of commercial quartz dust, (Fig. 1), as previously evidenced (Murashov and Demchuk 2005). Specific surface area (SSA, Kr-BET) and particle size distribution, evaluated by dynamic light scattering (DLS) and flow particle image analysis (FPIA), of the synthetic samples, were comparable with the positive control quartz (Table 1). The SSA of gQ-f was slightly lower than that of $\mathrm{gQ}$, because the latter contains a slightly larger fraction of fine particles, as evidenced by the DLS analysis.

$\%$ Hemolysis $=\frac{(\text { Sample OD }- \text { Negative Control Average OD })}{(\text { Positive Control Average OD }- \text { Negative Control Average OD })} \times 100$

where OD is the optical density or absorbance.
The zeta potential of particles (ELS, measured in the various medium at specific $\mathrm{pH}$ ), here used to describe the 
Table 1 Main physico-chemical properties of the investigated samples. Synthetic samples (gQ, as grown; gQ-f, fractured) were characterized and compared to a commercial quartz dust (cQ-f)

\begin{tabular}{|c|c|c|c|c|c|c|c|c|}
\hline \multirow[t]{2}{*}{ Sample } & \multirow[t]{2}{*}{ Origin } & \multirow[t]{2}{*}{ Surface state } & \multirow{2}{*}{$\begin{array}{l}\text { FPIA Size }^{\mathrm{a}} \\
(\mu \mathrm{m} \pm \text { s.d. })\end{array}$} & \multirow{2}{*}{$\begin{array}{l}\text { DLS diameter } \\
(\mu \mathrm{m} \pm \text { s.d.) }(\mathrm{PDI})\end{array}$} & \multirow[t]{2}{*}{$\operatorname{SSA}^{\mathrm{c}}\left(\mathrm{m}^{2 /} \mathrm{g}\right)$} & \multicolumn{3}{|c|}{$\zeta$-potential $(\mathrm{mV} \pm$ s.d. $)$} \\
\hline & & & & & & $\overline{\text { s.f. RPMI }}{ }^{\mathrm{d}}$ & cRPMI $^{\mathrm{e}}$ & $\overline{0.01 \mathrm{NaCl}^{\mathrm{f}}}$ \\
\hline $\mathrm{gQ}$ & Synthetic & As-grown & $1.3 \pm 2.3$ & $\begin{array}{l}0.89 \pm 0.23 \\
(0.507)\end{array}$ & 5.8 & ca. 0 & $-11 \pm 1$ & $-45 \pm 2$ \\
\hline$g Q-f$ & Synthetic & Fractured & $1.2 \pm 0.7$ & $\begin{array}{l}1.55 \pm 0.18 \\
(0.485)\end{array}$ & 4.5 & ca. 0 & $-12 \pm 1$ & $-50 \pm 1$ \\
\hline$c Q-f$ & Commercial & Fractured & $1.0 \pm 1.2$ & $\begin{array}{l}1.74 \pm 0.20 \\
(0.295)\end{array}$ & 4.3 & ca. 0 & $-10 \pm 1$ & $-59 \pm 2$ \\
\hline
\end{tabular}

Size distribution of crystals was evaluated in Milli-Q water by flow particle image analyser and in cRPMI by dynamic light scattering. Specific surface area was evaluated via BET method, by $\mathrm{Kr}$ adsorption. The $\zeta$-potential was evaluated in the different medium at specific $\mathrm{pH}$, by electronic light scattering

${ }^{a}$ Measured by flow particle image analyser (FPIA) in ultrapure $\mathrm{H}_{2} \mathrm{O}$

${ }^{b}$ Measured by dynamic light scattering (DLS) in + RPMI + 10\% FBS, the polydispersity index (PDI) is reported in brackets

${ }^{\mathrm{c}}$ Measured by Kr-BET method

${ }^{\mathrm{d}}$ Measured by electrophoretic light scattering (ELS) in serum free RPMI (pH ca. 8)

${ }^{\mathrm{e}}$ Measured by electrophoretic light scattering (ELS) in RPMI + 10\% FBS (pH ca. 8)

${ }^{\mathrm{f}}$ Measured by electrophoretic light scattering (ELS) in $0.01 \mathrm{~m} \mathrm{NaCl}(\mathrm{pH} 4.5)$
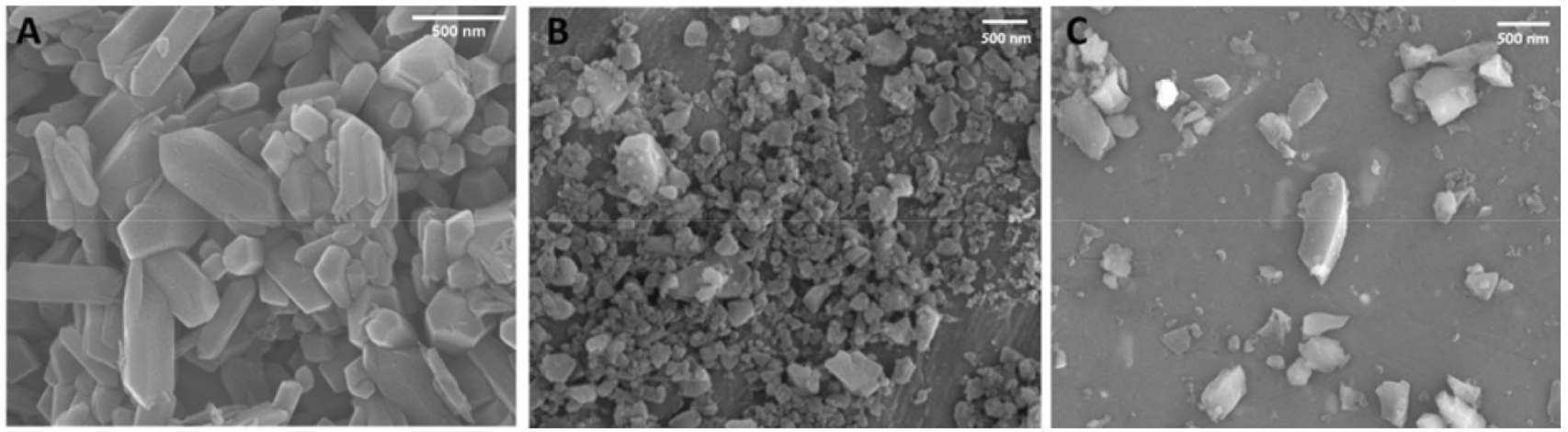

Fig. 1 FE-SEM imaging of gQ, gQ-f and cQ-f quartz samples. a Synthetic regular quartz crystals (gQ) show as-grown, flat and smooth surfaces; fractured quartz crystals $(\mathbf{b}, \mathbf{c})$ (gQ-f and cQ-f, respectively) exhibit irregular surfaces and the typical fractures due to mechanical fracturing

average acidity of surface silanols (Pavan et al. 2017), acidic moieties with a potential for H-bonding, showed no significant differences among the set of samples, for the same medium. As expected, the zeta potential of particles dispersed in saline $(0.01 \mathrm{M} \mathrm{NaCl})$ at $\mathrm{pH} 4.5$, which represents the lysosomal $\mathrm{pH}$, was strongly negative $(<-40 \mathrm{mV})$. Only small differences among zeta potential, namely gQ being less negatively charged than $\mathrm{gQ}-\mathrm{f}$ and $\mathrm{cQ}-\mathrm{f}$, were detected. These differences were assigned to the different average acidity of the surface silanols exposed at the quartz surface. Silanols $(\equiv \mathrm{Si}-\mathrm{OH})$ are known to behave in aqueous media as weak monoprotic Brønsted acid, exhibiting a dissociation constant that is dependent on the silanol structural arrangement with respect to neighbouring silanols (Hiemstra et al. 1989; Bolis et al. 1997; Pavan et al. 2017). Silanols at silica surface can thus be described as families of silanols, sharing similar acidic properties that impart as a whole a specific surface charge (Pavan et al., under review/ unpublished work). Thus, the slight difference in surface charge between gQ and gQ-f crystals suggests the occurrence of different silanol families with different chemical properties in the quartz particles, that were induced by fracturing and confirms previous findings (Turci et al. 2016). Such a difference was not observed when particles were dispersed in serum-free RPMI where, consistent with the much higher ionic strength of RPMI, all samples exhibited a zeta potential close to the point of zero charge (pzc). The measure of the zeta potential was also used to evaluate the adsorption of serum proteins on the quartz surface (Turci et al. 2010). Upon dispersion of particles in complete RPMI, all quartz samples exhibited a negative zeta potential (ca. $-10 \mathrm{mV}$ ), compatible with the 


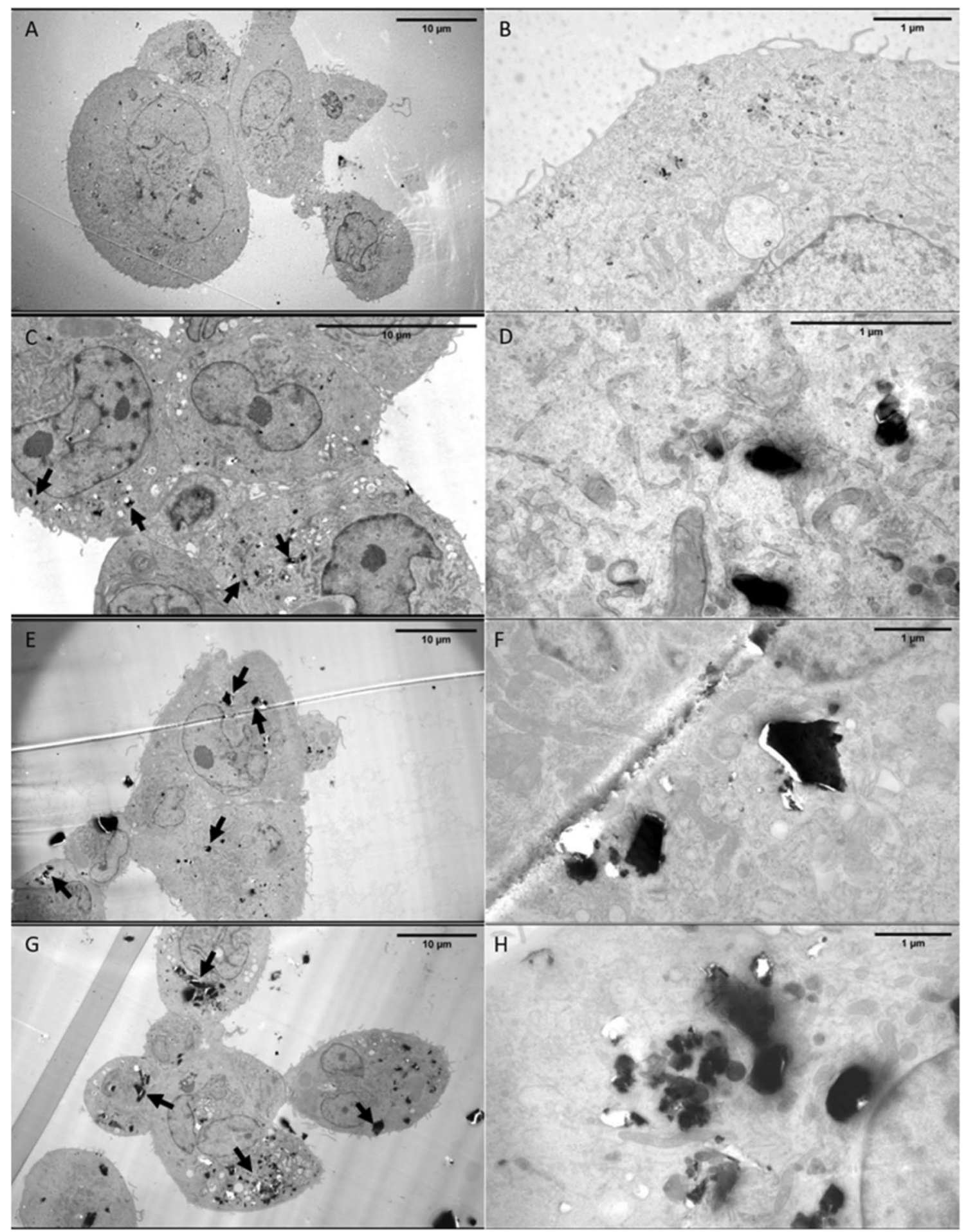

Fig. 2 Representative images by transmission electron microscopy (TEM) of differentiated THP-1 human macrophages exposed to quartz particles. Cells were exposed to synthetic $(\mathbf{c}, \mathbf{d})$ as-grown (gQ) and $(\mathbf{e}, \mathbf{f})$ fractured $(\mathrm{gQ}-\mathrm{f})$ quartz particles $(50 \mu \mathrm{g} / \mathrm{ml})$ for $24 \mathrm{~h} . \mathbf{a}, \mathbf{b})$ show equivalent images of untreated cells, and $(\mathbf{g}, \mathbf{h})$ cells exposed to a positive control (cQ-f). Electron microscopy confirmed that all types of particles (black arrows) were internalized by macrophages. Scale bars: $10 \mu \mathrm{m}(\mathbf{a}, \mathbf{c}, \mathbf{e}, \mathbf{g})$, and $1 \mu \mathrm{m}(\mathbf{b}, \mathbf{d}, \mathbf{f}, \mathbf{h})$ 
adsorption of serum proteins on the particle surface and the formation of the protein corona.

\section{As-grown and fractured crystals are both internalized by human macrophages}

The uptake and cytotoxicity of the different quartz particles were evaluated on PMA-differentiated THP-1 human monocytes, here chosen as a common model for human alveolar macrophages (Theus et al. 2004; Wottrich et al. 2004; Kletting et al. 2018). Transmission electron microscopy (TEM) of thin cross-sections of quartz-incubated and fixated cells indicated that all the samples were internalized by the macrophages (Fig. 2), confirming the previous finding in murine macrophages (Turci et al. 2016). To take into account the hardness and particle dimension of quartz, sections were prepared with a larger thickness than conventional bio-TEM sections. No evidence of particles absorbed on the outer cell membrane was found. Inside the cells, both single particles and micrometric aggregates could be visualized. Due to the larger thickness of the sections and also the high density of the particles with respect to the cellular background, it was not clear whether the internalized particles were enclosed in vesicles, as expected following some form of endocytosis (Fig. 2d, f, h show details at higher magnification). In addition, section thickness impaired the observation of lysosomes, which usually are easy to recognize as darker organelles inside cells by TEM.

\section{Fractured quartz reduces cell viability and induces phagolysosomal alterations}

The impact of quartz on macrophage metabolic activity upon $24 \mathrm{~h}$ exposure to increasing doses of the different quartz particles was investigated by the MTT assay in complete medium. In addition, since particle uptake is usually followed by the trafficking of the internalized materials to the lysosomes (Rejman et al. 2004; Nel et al. 2009; Salvati et al. 2011; Wang et al. 2013; Sabella et al. 2014), we evaluated whether alterations at phagolysosomal level could be detected. The acidic compartment of macrophages exposed to quartz was stained with the acidotropic probe Lyso Tracker Red (Fig. 3) (Wang et al. 2013). Lyso Tracker staining is often used to detect lysosomal alterations (Wang et al. 2013, 2018). An increase in its intensity upon treatment is a sign of an increase in acidity of the lysosomal compartment or increase in number or volume of lysosomes. Loss of Lyso Tracker staining can instead be a sign of lysosomal membrane permeabilization or a consequence of cell death. Cells exposed to as-grown crystals (gQ) did not show any significant metabolic or phagolysosomal alteration, even at the highest dose (Fig. 3). On the contrary, exposure to fractured synthetic crystals (gQ-f) induced a considerable reduction of cell metabolic activity and a strong increase in Lyso Tracker intensity (Fig. 3a, b). In particular, the impact on phagolysosomes was appreciable already at low particle dosage, with a clear dose-response trend and effects similar to what observed with cQ-f quartz. The flow cytometry analysis also revealed a cellular sub-population with loss of Lyso Tracker staining at higher doses (Fig. 3c, orange curves, corresponding to particle concentration of $100 \mu \mathrm{g} /$ $\mathrm{ml}$ ), in particular in the case of cells treated with fractured quartz dusts (gQ-f and cQ-f), possibly due to dying cells. This is largely consistent with the cytotoxicity observed in the same conditions (Fig. 3a). Overall, these results clearly indicated that fractured quartz dusts induced a decrease in cell metabolic activity and strong alterations of the acidic compartment of THP-1 macrophages.

\section{Fractured quartz cytotoxicity is quenched when phagocytosis is prevented}

To investigate whether cytotoxicity was induced via interactions at the outer cell membrane level or following particle internalization, the MTT and Lyso Tracker Red assays were repeated in energy depleted conditions to suppress active uptake processes (Rejman et al. 2004). Cells were exposed for $4 \mathrm{~h}$ to quartz in standard $\left(37^{\circ} \mathrm{C} / 4 \mathrm{~h}\right)$ or energy-depleted $\left(4{ }^{\circ} \mathrm{C} / 4 \mathrm{~h}\right)$ conditions, then washed to remove extracellular particles, and incubated at $37{ }^{\circ} \mathrm{C}$ for $20 \mathrm{~h}$, prior to MTT assay and Lyso Tracker staining (Fig. 4).

The cytotoxicity and phagolysosome alterations resulting after $37{ }^{\circ} \mathrm{C} / 4 \mathrm{~h}+37{ }^{\circ} \mathrm{C} / 20 \mathrm{~h}$ exposure (Fig. 4a, c) were similar to what observed after the conventional incubation ( $37^{\circ} \mathrm{C} / 24 \mathrm{~h}$ exposure, Fig. 3). On the contrary, cytotoxicity and phagolysosome alterations were almost completely suppressed when uptake was impaired $\left(4{ }^{\circ} \mathrm{C} / 4 \mathrm{~h}+37^{\circ} \mathrm{C} / 20 \mathrm{~h}\right)$ (Fig. 4b, d), indicating that both cellular responses are induced by fractured quartz only upon active internalization by THP-1 macrophages.

\section{Hemolytic activity but not cytotoxicity is suppressed when the surface of fractured quartz is coated with FBS proteins}

To gain insights on whether the interaction of quartz particles with membranes is modulated by the presence of biomolecules, we compared the effect of quartz dust in the presence and absence of FBS, as a source of proteins. When quartz dusts come into contact with the lung lining fluid, the formation of a biomolecule layer, in particular proteins, possibly covering the surface of quartz is expected. To gain evidence of the formation of a protein-coating, the surface charge of quartz dust incubated with FBS was assessed. The shift in zeta-potential of ca. - $10 \mathrm{mV}$ (see Table 1) confirms the formation of a protein corona on FBS-incubated 

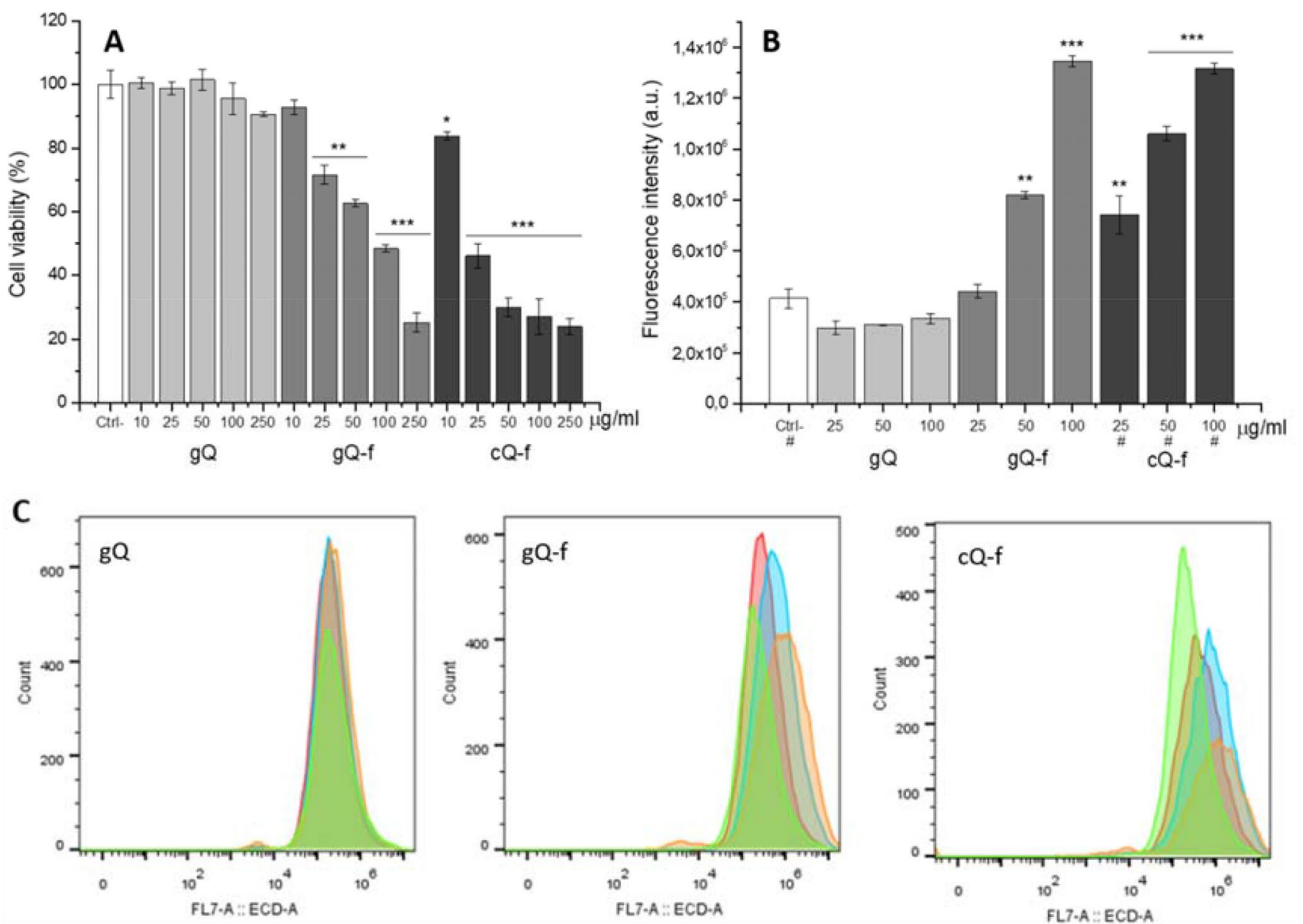

Fig. 3 Impact of quartz particles on cell viability (a) and lysosome alteration $(\mathbf{b}, \mathbf{c})$, after $24 \mathrm{~h}$ exposure to increasing doses of quartz particles in complete RPMI. The cell viability, investigated by MTT assay (a), is expressed as a percentage with respect to untreated cells. The mitochondrial activity significantly decreased only upon exposure to fractured quartz (gQ-f and cQ-f). Data are the mean $( \pm S D)$ of four biological replicates of one representative experiment out of three. Impact on phagolysosomes $(\mathbf{b}, \mathbf{c})$ was measured by incubation of differentiated THP-1 macrophages with quartz, followed by staining with Lyso Tracker Red dye. Fluorescence variation was evaluated by flow cytometry: mean fluorescence (b) and corresponding Lyso Tracker intensity distributions (c). Quartz concentrations are identified by the colour code described as follows: red: $25 \mu \mathrm{g} /$ ml; cyan: $50 \mu \mathrm{g} / \mathrm{ml}$; orange: $100 \mu \mathrm{g} / \mathrm{ml}$; green: untreated cells. The Lyso Tracker Red data shown is the result of three biological replicates of one representative experiment out of three. Cell counts ranged from ca. 7600 to 20,000 . Samples where less than 20,000 cells were counted are highlighted by a hash mark (\#). For synthetic quartz samples (gQ and gQ-f), 20,000 cells were counted on average, for each dosage. Because of cytotoxicity, fewer cells were counted for cQ-f $(25 \mu \mathrm{g} / \mathrm{ml}: 12,728$ cells; $50 \mu \mathrm{g} / \mathrm{ml}: 13,575$ cells: $100 \mu \mathrm{g} / \mathrm{ml}$ : 7680 cells). Untreated cells ranged from 16,300 to 18,500 . Differences between negative control and quartz-exposed cells were evaluated with one-way ANOVA, followed by Tukey's post-hoc analysis. $p$ values $<0.05$ were considered statistically significant. $* p<0.05$, $* * p<0.01, * * * p<0.001 \mathrm{vs}$. control not exposed to quartz quartz. The capacity of the fractured synthetic sample (gQf) to induce hemolysis was assessed by exposing RBCs to particles in the presence of increasing concentrations of FBS (Fig. 5).

Importantly, FBS markedly reduced the hemolytic activity of fractured crystals. This effect was observed already at the lowest concentration of FBS and attained a complete suppression of the hemolytic activity at $0.3 \%$. To investigate the role of particle surface in quartz cytotoxicity, we exposed THP-1 macrophages to the quartz samples in presence of $10 \%$ FBS in the medium (+FBS) or in serum-free medium (- FBS). Cytotoxicity was assessed after 4 and $24 \mathrm{~h}$ by MTT assay (Fig. 6a, b), and after $4 \mathrm{~h}$ by PI assay (Fig. 6c), used here as an additional marker of cytotoxicity. The overall cytotoxicity, as expected, increased upon the incubation with fractured crystals. The cellular metabolic activity of the cells, assessed by MTT assay, significantly decreased after 4 and $24 \mathrm{~h}$ incubation time. Interestingly, at both exposure times ( 4 and $24 \mathrm{~h}$ ), a similar cell viability was observed when cells were exposed to fractured quartz dusts in medium with proteins or serum-free medium. The PI assay further confirmed that only fractured quartz is cytotoxic, and allowed us to evidence a small but significant 

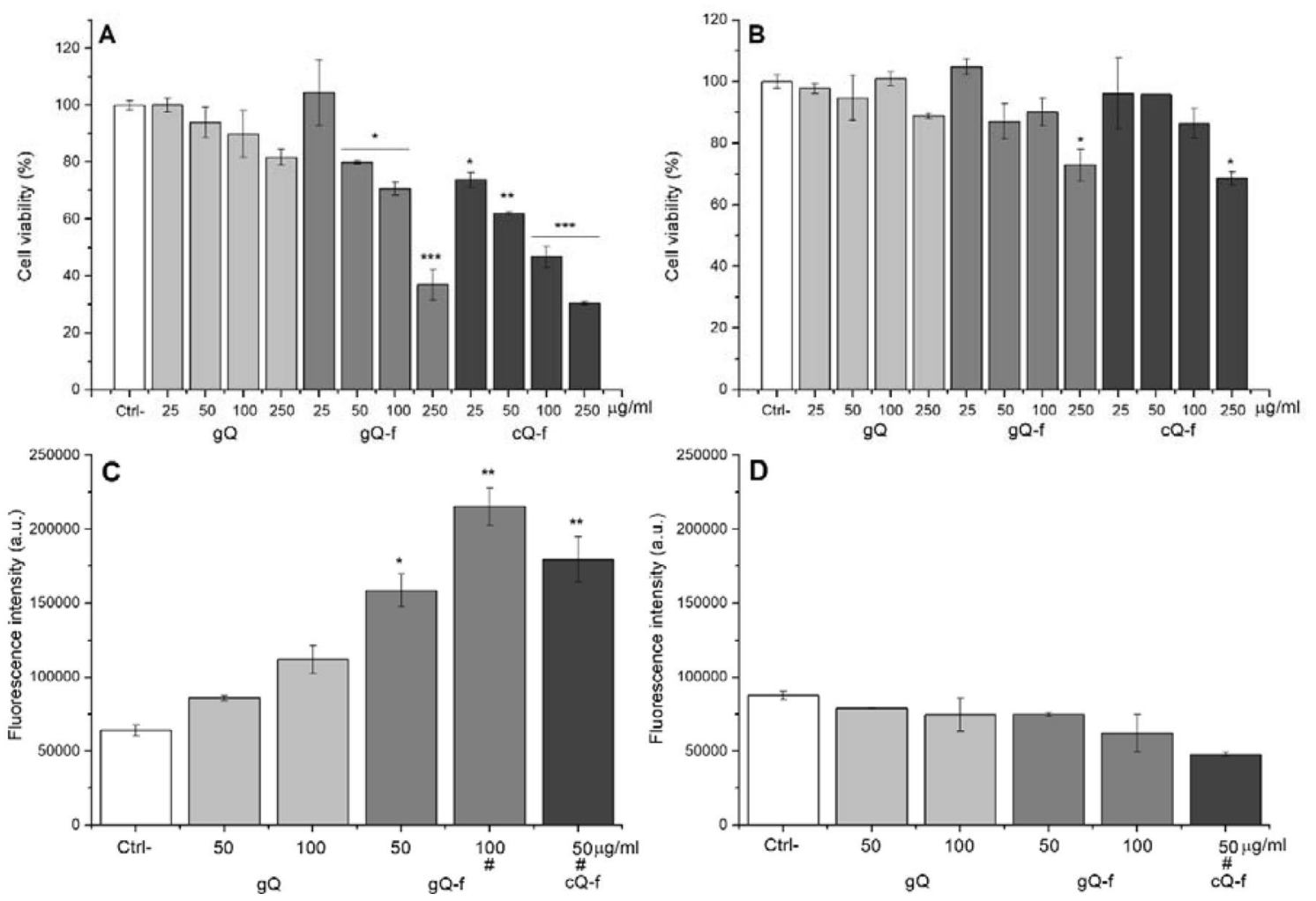

Fig. 4 PMA-differentiated THP-1 macrophages were exposed for $4 \mathrm{~h}$ to increasing doses of quartz particles in cRPMI, in standard $(\mathbf{a}, \mathbf{c})$ or energy depleted $(\mathbf{b}, \mathbf{d})$ conditions, followed by particle removal and further incubation at $37^{\circ} \mathrm{C}$ for $20 \mathrm{~h}$. Impact on cell viability was evaluated via MTT $(\mathbf{a}, \mathbf{b})$. Data are from one representative experiment, using four replicates per dose, and are expressed as a percentage with respect to untreated cells. Phagolysosome alteration $(\mathbf{c}, \mathbf{d})$ was investigated by staining cells with Lyso Tracker Red dye, and flow cytom-

difference in $\%$ of PI-positive cells when macrophages were exposed in + FBS or-FBS media.

\section{Discussion}

The permeabilization of the lysosomal membrane can lead to the intracellular inflammasome activation and release of pro-inflammatory mediators (IL-8, IL-1 $\beta$ ) (Mossman and Churg 1998; Latz et al. 2013; Joshi et al. 2015; Rabolli et al. 2015; Sharma and Kanneganti 2016; Hindman and Ma 2019). These events are observed upon prolonged exposure to respirable crystalline silica (RCS) and are held responsible for the induction of the persistent lung inflammation resulting, in the long term, in severe pathological outcomes, including lung cancer (Albrecht et al. 2007).

Recent works investigating the adverse outcome pathway (AOP) for quartz-induced lung pathologies (Pavan and Fubini 2017; Pavan et al. 2019) proposed the interaction of quartz with the phagolysosomal membrane as

etry. Data are the mean $( \pm S D)$ of one representative experiment out of three, with two replicates for each condition. Counted cells ranged from ca. 15,000 to 20,000 . Samples where less than 20,000 cells were counted are highlighted by a hash mark (\#). Differences between negative control and quartz-exposed cells were evaluated with oneway ANOVA, followed by Tukey's post-hoc analysis. $p$ values $<0.05$ were considered statistically significant. $* p<0.05, \quad * * p<0.01$, $* * * p<0.001$ vs. control not exposed to quartz

one of the key events in quartz toxicity. In this work, we investigate the effects of quartz dusts on THP-1 monocytes PMA-differentiated into macrophages, chosen as a model for alveolar macrophages, and we focus on quartz impact on the phagolysosomal membrane. To understand how quartz initiates the inflammatory process in macrophages, we measured the membranolytic activity, the cytotoxicity, and the impact on phagolysosomes elicited by the as-grown and fractured quartz crystals. The modulation of these readouts by serum proteins adsorbed on the surface of quartz was also determined and allowed to propose an uptake-dependent mechanism of action for quartz in macrophages.

Quartz crystals with fractured surfaces, both synthetic and industrially produced, show a higher membranolytic activity than as-grown quartz dust, suggesting that the former might be able to induce a stronger destabilization of the macrophage membranes. Our data also indicate that all quartz dusts are internalized by THP-1 cell, but only quartz with fractured surfaces affects cell viability and 


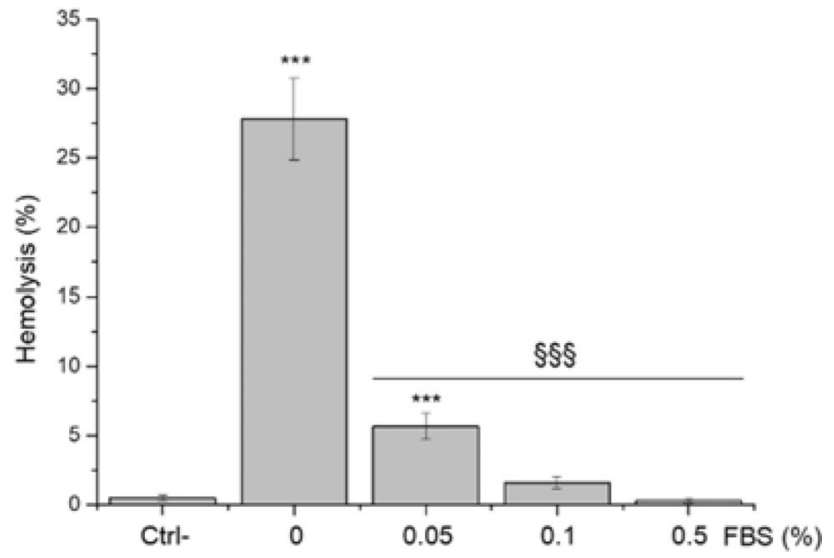

Fig. 5 Hemolytic activity of gQ-f in absence or presence of FBS. Quartz was incubated $30 \mathrm{~min}$ at $25^{\circ} \mathrm{C}$ with purified human red blood cells, in the presence of increasing concentrations of FBS $(0,0.05$, 0.1 and $0.5 \%$ ). FBS was not removed during RBCs exposure to particles. Dispersion in medium with protein reduced the hemolytic activity of quartz particles. Data were analysed with one-way ANOVA, followed by Tukey's post-hoc analysis. $p$ values $<0.05$ were considered statistically significant. ${ }^{*} p<0.05$, $* * p<0.01$, $* * * p<0.001$ vs. control not exposed to quartz. $\S p<0.05, \S \S p<0.01, \S \S \S p<0.001$ vs. hemolysis with no FBS (0\% FBS)

induce lysosome alterations and cell death. Such a different behaviour of rather similar specimens can be explained with the differences in surface chemistry between as-grown and fractured crystals, specifically due to the random distribution of surface functionalities (silanols and siloxanes) induced by mechanical fracturing (Turci et al. 2016; Pavan and Fubini 2017). Interestingly, the impairment of active uptake obtained with the pre-incubation of cell and quartz at $4{ }^{\circ} \mathrm{C}$, suppresses the cytotoxic effects observed for fractured samples, including lysosomal alterations. The reduction of cytotoxicity in energy-depleted cells suggests that the toxic activity of quartz is elicited after internalization by macrophages, confirming a direct action of the fractured quartz particle surface on the phagolysosomal membrane, rather than on the outer cell membrane. A further proof that the detrimental quartz-membrane interactions take place primarily at a phagolysosomal level is given by the results obtained upon incubation of quartz with serum proteins (FBS). The suppression of the membranolytic activity when fractured quartz and RBCs are contacted in an FBS medium supports the hypothesis that serum proteins mask the surface reactive groups responsible for quartz membranolytic activity. This is in agreement with previous results (Cassel et al. 2008; Hornung et al. 2008; Pavan et al. 2014) and supports the masking effect observed with quartz coated with organic polymers (Bernstein et al. 2005; Peeters et al. 2014; Ziemann et al. 2017). On the contrary, the protein coating on fractured quartz did not modify the cell viability impact towards THP- 1 macrophages at 4 and $24 \mathrm{~h}$ (Fig. 4). The similar cytotoxicity which we observed for uncoated and protein-coated quartz suggests that a rapid removal of the protein coating occurs after particle trafficking in the lysosomes, where the lysosomal acidity and lytic enzymes can restore the pristine fractured surfaces of quartz and, in this way, its membranolytic activity. This is also supported by the results of the PI assay, in which the slightly lower cytotoxicity of protein-coated fractured particles, in comparison to what observed in serum-free media, suggests for an initial cleaning phase of quartz surfaces inside the phagolysosome, not yet completed at the shorter exposure time. The low surface area of quartz (ca. $5 \mathrm{~m}^{2} / \mathrm{g}$ ) accounts for this relatively rapid, yet biochemically similar, process in comparison to what has been previously evidenced for some nanoparticles accumulating in the phagolysosomes (Wang et al. 2013).

In some cases, the suppression of toxicity was observed upon protein corona formation also on amorphous silica nanoparticles (Lesniak et al. 2012; Tenzer et al. 2013; Leibe et al. 2019), but not all studies have confirmed this finding (Hsiao et al. 2019; Deville et al. 2020). The partial similarities between amorphous and crystalline silica may suggest the occurrence of common surface features on fractured quartz crystals and some amorphous silicas. In fact, it is known that the mechanical fracturing of quartz crystals may induce a partial amorphization of the surface (Nagelschmidt et al. 1952) with the formation of the so-called Beilby layer. This layer is formed when the surface reconstruction that immediately follows fracturing of $\mathrm{SiO}_{2}$ crystals takes place and is characterized by a pronounced structural and chemical heterogeneity of surface moieties, including silanols. The comparison of as-grown and fractured quartz surfaces evidenced that several parameters describing surface silanols, including the zeta potential and surface reactivity, significantly differed among the two solids (Turci et al. 2016). The different behaviour was explained by the chemical disorganization in the long-range spatial order of silanols introduced with fracturing. The interaction of the disorganized silanols with the lysosome membrane may represent the molecular initiating event (MIE) that triggers quartz cytotoxicity, as recently proposed by Pavan and Fubini (2017). These more heterogenous surfaces may be structurally similar to those of some amorphous silicas (Murashov et al. 2006; Rimola et al. 2013) and their occurrence may explain the cytotoxicity elicited by some amorphous silica particles after uptake and accumulation in the lysosomes (Hsiao et al. 2019; Deville et al. 2020). It would be interesting to study more in detail whether the different surface chemistry induced on quartz by fracturing is qualitatively comparable with the silanol pattern that occurs on the amorphous silica nanoparticle that shows cytotoxic effect.

Overall, our data confirm that: (1) quartz with fractured surfaces induces cytotoxicity and phagolysosomal alterations in human macrophages; (2) the quartz cytotoxic activity on 

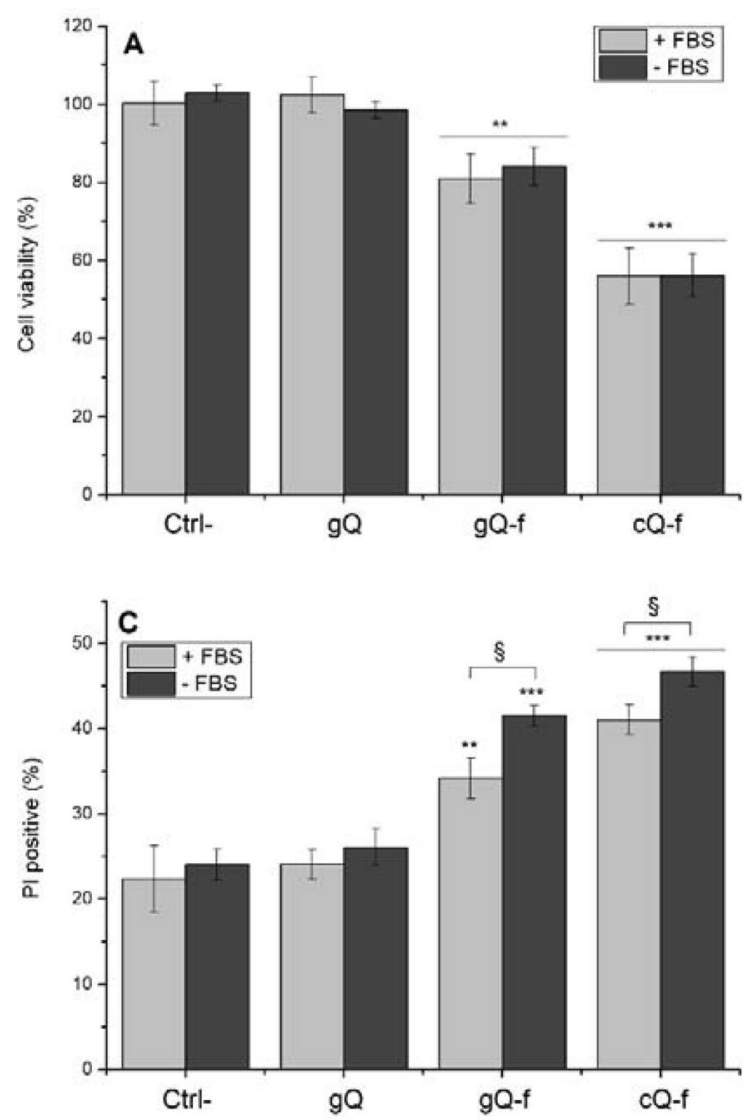

Fig. 6 Impact of FBS on quartz cytotoxicity was evaluated via MTT assay after (a) $4 \mathrm{~h}$ and (b) $24 \mathrm{~h}$ exposure, and (c) \% of PI-positive cells, as measured by staining with propidium iodide and flow cytometry ( $4 \mathrm{~h}$ exposure). THP-1 macrophages were exposed to particles $(100 \mu \mathrm{g} / \mathrm{ml})$ in presence of $10 \%$ FBS $(+$ FBS $)$ or in serum-free RPMI (- FBS). Cytotoxicity is observed for fractured samples only, as expected. Comparing + FBS and-FBS exposures, MTT readouts at both 4 (a) and $24 \mathrm{~h}$ (b) were similar, while PI assay (c) showed small differences for fractured particles only. MTT data are from one representative experiment out of three, using four replicate wells per concentration, and are expressed as a percentage with respect to the

THP-1 macrophages is dependent on particle uptake; and (3) the cytotoxic activity of quartz relies on direct interactions of fractured quartz surfaces with the phagolysosomal membrane.

The loss of long-range order surface moieties (silanols and siloxanes) induced by the fracturing of regular crystals, macroscopically evidenced by the appearance of the typical conchoidal fractures of quartz (Murashov and Demchuk 2005), is here confirmed to be a key physico-chemical parameter in the toxicity of crystalline silica. In addition, we have gained new insights on the molecular initiating event of quartz inflammatory mechanisms (Pavan and Fubini 2017). Indeed, we observed that the detrimental effect of quartz is induced only when quartz particles are internalized, possibly

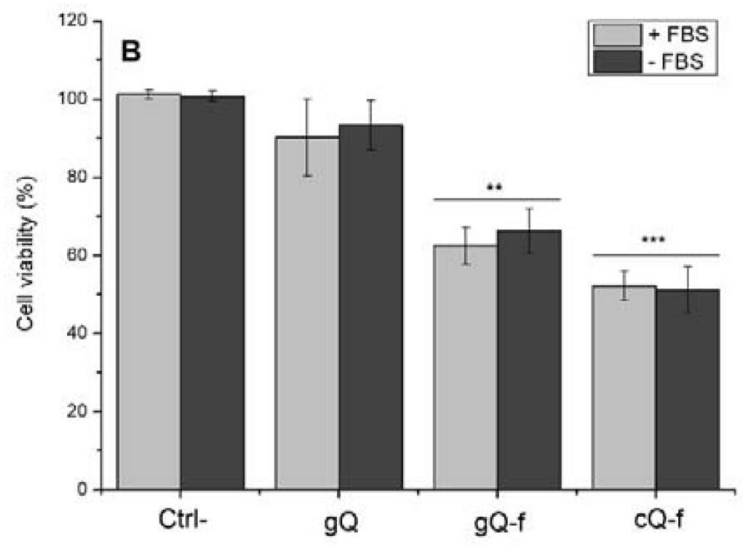

values of untreated cells. PI assay data result from one representative experiment out of three, using four replicates. A variable number of cells ranging from a minimum of ca. 7000 (cQ-f) to a maximum of ca. $12,000(\mathrm{gQ})$ were counted. Data are expressed as means $( \pm \mathrm{SD})$. Differences between negative control and quartz exposed-cells and + FBS vs.-FBS were evaluated with one-way ANOVA, followed by Tukey's post-hoc analysis. $p$ values $<0.05$ were considered statistically significant. $* p<0.05, * * p<0.01, * * * p<0.001$ vs. control not exposed to quartz. $\S p<0.05, \S \S p<0.01, \S \S \S p<0.001$ for + FBS vs.-FBS

when the phagolysosomal membrane is directly interacting with fractured quartz surfaces.

The molecular mechanisms leading to the observed alterations remain to be investigated. However, the results presented here support the hypothesis that quartz particles, after being internalized and cleaned up from adsorbed extracellular molecules in the phagolysosomes, may induce lysosomal membrane permeabilization (Hornung et al. 2008). Since the activation of NALP-3 inflammasome by quartz particles requires lysosome membrane damage (He et al. 2016), our results suggest that the surface chemistry of quartz crystals may directly determine membrane destabilization, starting the well-described inflammatory process related to quartz pathological outcomes. The results obtained with this work confirm the improved model mechanism for quartz toxicity 
on human macrophages (Pavan et al. 2014; Turci et al. 2016; Pavan and Fubini 2017), and advance our knowledge on the alterations induced by fractured quartz on the phagolysosomal membrane, that are responsible for the initiation of quartz inflammogenic effect (Hornung et al. 2008).

\section{Conclusions}

One of the most robust paradigm about the origin of the toxicological response to quartz dust involves the interaction of particles internalized by macrophages with the phagolysosomal membrane as the molecular initiating event (MIE) of quartz-induced cytotoxic and inflammatory response (Pavan and Fubini 2017). In the present work, we have observed that the internalization of quartz crystals by THP-1 macrophages resulted in cytotoxic effects, including a strong impact at the lysosomal level, only when quartz is fractured. Cytotoxicity was quenched when the phagocytic activity of macrophages was prevented. In parallel, we observed that FBS suppressed the membranolytic activity, but not cytotoxicity, of fractured quartz, suggesting that quartz membrane lysis takes place in the phagolysosomes, following removal of proteins adsorbed on the particle surface. This led us to conclude that the interactions of the fractured crystal surfaces with the inner side of the phagolysosomal membrane, leading to its destabilization, are likely the cause of the observed impact on cell viability. On a broader level, this work suggests that toxic surface features of quartz could be predicted by a molecular knowledge of the surface chemistry of the dust. New investigations are currently being carried out to unveil the chemical nature of the surface features responsible for the membranolytic and cytotoxic activity of quartz (Pavan et al. 2019, Pavan et al., under review/unpublished work).

Acknowledgements We kindly thank Prof. Dominique Lison (LTAP, Université catholique de Louvain, Belgium) for fruitful discussions that largely improved the manuscript. Transmission electron microscopy has been performed in the UMCG Microscopy and Imaging Center (UMIC), University of Groningen, the Netherlands.

\begin{abstract}
Author contributions RL designed and carried out the experiments, under the supervision of AS at the University of Groningen, and wrote the manuscript. CP synthesized quartz crystals, performed part of physico-chemical characterization, and carried out hemolysis assay. HY carried out the TEM imaging on fixed cells. MT performed part of physico-chemical characterization. AS designed the cell experiments, interpreted the data, and wrote the manuscript. FT supervised the whole project, interpreted the data, and wrote the manuscript. All authors read and approved the final manuscript.
\end{abstract}

Funding Funding for this project was received from the European Association of Silica Producers (EUROSIL) to RL, CP, MT, and FT, and from H2020-MSCA-COFUND-2015 project ALERT (Grant Agreement number: 713482 ) to HY and AS.
Data availability The datasets generated during and/or analysed during the current study are available from the corresponding author on reasonable request.

\section{Compliance with ethical standards}

Conflict of interest The authors declare that they have no conflict of interest.

Ethical standards The manuscript does not contain clinical studies or patient data.

Open Access This article is licensed under a Creative Commons Attribution 4.0 International License, which permits use, sharing, adaptation, distribution and reproduction in any medium or format, as long as you give appropriate credit to the original author(s) and the source, provide a link to the Creative Commons licence, and indicate if changes were made. The images or other third party material in this article are included in the article's Creative Commons licence, unless indicated otherwise in a credit line to the material. If material is not included in the article's Creative Commons licence and your intended use is not permitted by statutory regulation or exceeds the permitted use, you will need to obtain permission directly from the copyright holder. To view a copy of this licence, visit http://creativecommons.org/licenses/by/4.0/.

\section{References}

Albrecht C, Höhr D, Haberzettl P et al (2007) Surface-dependent quartz uptake by macrophages: potential role in pulmonary inflammation and lung clearance. Inhal Toxicol 19(Suppl 1):39-48

Allison AC (1966) An examination of the cytotoxic effects of silica on macrophages. J Exp Med 124:141-154

American Thoracic Society (1997) Adverse effects of crystalline silica exposure. Am J Respir Crit Care Med 155(2):761-768

Bernstein D, Castranova V, Donaldson K et al (2005) Testing of fibrous particles: short-term assays and strategies. Inhal Toxicol 17(10):497-537

Bolis V, Cavenago A, Fubini B (1997) Surface heterogeneity on hydrophilic and hydrophobic silicas: water and alcohols as probes for H-bonding and dispersion forces. Langmuir 13:895-902

Bolis V, Fubini B, Marchese L et al (1991) Hydrophilic and hydrophobic sites on dehydrated crystalline and amorphous silicas. J Chem Soc Faraday Trans 87:497

Cassel SL, Eisenbarth SC, Iyer SS et al (2008) The Nalp3 inflammasome is essential for the development of silicosis. Proc Natl Acad Sci 105:9035-9040

Castranova V (2004) Signaling pathways controlling the production of inflammatory mediators in response to crystalline silica exposure: role of reactive oxygen/nitrogen species. Free Radic Biol Med 37:916-925

Dalal NS, Shi XL, Vallyathan V (1990) ESR spin trapping and cytotoxicity investigations of freshly fractured quartz: mechanism of acute silicosis. Free Radic Res Commun 9:259-266

Daniel LN, Mao Y, Wang TC et al (1995) DNA strand breakage, thymine glycol production, and hydroxyl radical generation induced by different samples of crystalline silica in vitro. Env Res 71:60-73

Deville S, Honrath B, Tran QTD et al (2020) Time-resolved characterization of the mechanisms of toxicity induced by silica and amino-modified polystyrene on alveolar-like macrophages. Arch Toxicol 94:173-186 
Dostert C, Pétrilli V, Van Bruggen R et al (2008) Innate immune activation through Nalp3 inflammasome sensing of asbestos and silica. Science 320(5876):674-677

Duffin R, Gilmour PS, Schins RP et al (2001) Aluminium lactate treatment of DQ12 quartz inhibits its ability to cause inflammation, chemokine expression, and nuclear factor-kappaB activation. Toxicol Appl Pharmacol 176:10-17

Dunn WA, Hubbard AL, Aronson NN (1980) Low temperature selectively inhibits fusion between pinocytic vesicles and lysosomes during heterophagy of $125 \mathrm{I}$-asialofetuin by the perfused rat liver. J Biol Chem 255:5971-5978

Fenoglio I, Fubini B, Tiozzo R, Di Renzo F (2000) Effect of micromorphology and surface reactivity of several unusual forms of crystalline silica on the toxicity to a monocyte-macrophage tumor cell line. Inhal Toxicol 12:81-89

Fubini B, Hubbard A (2003) Reactive oxygen species (ROS) and reactive nitrogen species (RNS) generation by silica in inflammation and fibrosis. Free Radic Biol Med 34:1507-1516

Gerashchenko BI, Gunko VM, Gerashchenko II et al (2002) Probing the silica surfaces by red blood cells. Cytometry 49:56-61

Gerlier D, Thomasset N (1986) Use of MTT colorimetric assay to measure cell activation. J Immunol Methods 94:57-63

Gilberti RM, Joshi GN, Knecht DA (2008) The phagocytosis of crystalline silica particles by macrophages. Am J Respir Cell Mol Biol 39:619-627

Giordano G, van den Brûle S, Lo RS et al (2010) Type I interferon signaling contributes to chronic inflammation in a murine model of silicosis. Toxicol Sci 116:682-692

Hamilton RF, Thakur SA, Holian A (2008) Silica binding and toxicity in alveolar macrophages. Free Radic Biol Med 44:1246-1258

He Y, Hara H, Núñez G (2016) Mechanism and regulation of NLRP3 inflammasome activation. Trends Biochem Sci 41:1012-1021

Hemenway D, Absher A, Fubini B et al (1994) Surface functionalities are related to biological response and transport of crystalline silica. Ann Occup Hyg 38:447-454

Hiemstra T, De Wit JCM, Van Riemsdijk WH (1989) Multisite proton adsorption modeling at the solid/solution interface of (hydr) oxides: a new approach. II. Application to various important (hydr)oxides. J Colloid Interface Sci 133:105-117

Hindman B, Ma Q (2019) Carbon nanotubes and crystalline silica stimulate robust ROS production, inflammasome activation, and IL-1 $\beta$ secretion in macrophages to induce myofibroblast transformation. Arch Toxicol 93:887-907

Hiraiwa K, Van Eeden SF (2013) Contribution of lung macrophages to the inflammatory responses induced by exposure to air pollutants. Mediat Inflamm 2013:619523

Hornung V, Bauernfeind F, Halle A et al (2008) Silica crystals and aluminum salts activate the NALP3 inflammasome through phagosomal destabilization. Nat Immunol 9:847-856

Hsiao IL, Fritsch-Decker S, Leidner A et al (2019) Biocompatibility of amine-functionalized silica nanoparticles: the role of surface coverage. Small 15(10):e1805400

Hughes CS, Colhoun LM, Bains BK et al (2015) Extracellular cathep$\sin \mathrm{S}$ and intracellular caspase 1 activation are surrogate biomarkers of particulate-induced lysosomal disruption in macrophages. Part Fibre Toxicol 13:19

IARC-International Agency for Research on Cancer (2012). Arsenic, metals, fibres and dusts. Vol. 100C. IARC monographs on the evaluation of carcinogenic risks to humans.**

Joshi GN, Gilberti RM, Knecht DA (2017) Single cell analysis of phagocytosis, phagosome maturation, phagolysosomal leakage, and cell death following exposure of macrophages to silica particles. Methods Mol Biol 1519:55-77

Joshi GN, Goetjen AM, Knecht DA (2015) Silica particles cause NADPH oxidase-independent ROS generation and transient phagolysosomal leakage. Mol Biol Cell 26(18):3150-3164
Kletting S, Barthold S, Repnik U et al (2018) Co-culture of human alveolar epithelial (hAELVi) and macrophage (THP-1) cell lines. Altex 35:211-222

Latz E, Xiao TS, Stutz A (2013) Activation and regulation of the inflammasomes. Nat Rev Immunol 13:397-411

Leibe R, Hsiao IL, Fritsch-Decker S et al (2019) The protein corona suppresses the cytotoxic and pro-inflammatory response in lung epithelial cells and macrophages upon exposure to nanosilica. Arch Toxicol 93:871-885

Lesniak A, Fenaroli F, Monopoli MP et al (2012) Effects of the presence or absence of a protein corona on silica nanoparticle uptake and impact on cells. ACS Nano 6:5845-5857

Leung K, Nielsen I, Criscenti L (2009) Elucidating the bimodal acid base behavior of the water- silica interface from first principles. J Am Chem Soc 131:18358-18365

Lison D, Laloy J, Corazzari I et al (2009) Sintered indium-tinoxide (ITO) particles: a new pneumotoxic entity. Toxicol Sci 108:472-481

Lu S, Duffin R, Poland C et al (2009) Efficacy of simple short-term in vitro assays for predicting the potential of metal oxide nanoparticles to cause pulmonary inflammation. Environ Health Perspect 117:241-247

Mossman BT, Churg A (1998) Mechanisms in the pathogenesis of asbestosis and silicosis. Am J Respir Crit Care Med 157:1666-1680

Murashov VV, Demchuk E (2005) A comparative study of unrelaxed surfaces on quartz and kaolinite, using the periodic density functional theory. J Phys Chem B 109:10835-10841

Murashov V, Harper M, Demchuk E (2006) Impact of silanol surface density on the toxicity of silica aerosols measured by erythrocyte haemolysis. J Occup Environ Hyg 3:718-723

Nagelschmidt G, Gordon RL, Griffin OG (1952) Surface of finelyground silica. Nature 169:539-540

Nel AE, Mädler L, Velegol D et al (2009) Understanding biophysicochemical interactions at the nano-bio interface. Nat Mater 8:543-557

Nolan RP, Langer AM, Harington JS et al (1981) Quartz hemolysis as related to its surface functionalities. Environ Res 26:503-520

Parks CG, Conrad K, Cooper GS (1999) Occupational exposure to crystalline silica and autoimmune disease. Environ Health Perspect 107:793-802

Pastero L, Turci F, Leinardi R et al (2016) Synthesis of $\alpha$-quartz with controlled properties for the investigation of the molecular determinants in silica toxicology. Cryst Growth Des 16:2394-2403

Pavan C, Delle Piane M, Gullo M et al (2019) The puzzling issue of silica toxicity: are silanols bridging the gaps between surface states and pathogenicity? Part Fibre Toxicol 16(1):32

Pavan C, Fubini B (2017) Unveiling the variability of "Quartz Hazard" in light of recent toxicological findings. Chem Res Toxicol 30:469-485

Pavan C, Rabolli V, Tomatis M et al (2014) Why does the hemolytic activity of silica predict its pro-inflammatory activity? Part Fibre Toxicol 11:76

Pavan C, Tomatis M, Ghiazza M et al (2013) In search of the chemical basis of the hemolytic potential of silicas. Chem Res Toxicol 26:1188-1198

Pavan C, Turci F, Tomatis M et al (2017) Z potential evidences silanol heterogeneity induced by metal contaminants at the quartz surface: Implications in membrane damage. Colloids Surf B Biointerfaces 157:449-455

Peeters PM, Eurlings IMJ, Perkins TN et al (2014) Silica-induced NLRP3 inflammasome activation in vitro and in rat lungs. Part Fibre Toxicol 11:58 
Pfau JC, Seib T, Overocker JJ et al (2012) Functional expression of system $\mathrm{x}(\mathrm{c})$ - is upregulated by asbestos but not crystalline silica in murine macrophages. Inhal Toxicol 24:476-485

Rabolli V, Lison D, Huaux F (2015) The complex cascade of cellular events governing inflammasome activation and IL- $1 \beta$ processing in response to inhaled particles. Part Fibre Toxicol 13:40

Rejman J, Oberle V, Zuhorn IS, Hoekstra D (2004) Size-dependent internalization of particles via the pathways of clathrin- and caveolae-mediated endocytosis. Biochem J 377:159-169

Rimola A, Costa D, Sodupe M et al (2013) Silica surface features and their role in the adsorption of biomolecules: computational modeling and experiments. Chem Rev 113:4216-4313

Sabella S, Carney RP, Brunetti V et al (2014) A general mechanism for intracellular toxicity of metal-containing nanoparticles. Nanoscale 6:7052-7061

Salvati A, Åberg C, dos Santos T et al (2011) Experimental and theoretical comparison of intracellular import of polymeric nanoparticles and small molecules: Toward models of uptake kinetics. Nanomedicine 7:818-826

Sayan M, Mossman BT (2015) The NLRP3 inflammasome in pathogenic particle and fibre-associated lung inflammation and diseases. Part Fibre Toxicol 13:51

Schins RPF, Knaapen AM, Cakmak GD et al (2002) Oxidant-induced DNA damage by quartz in alveolar epithelial cells. Mutat Res Genet Toxicol Environ Mutagen 517:77-86

Sellamuthu R (2011) Blood gene expression profiling detects silica exposure and toxicity. Toxicol Sci 122:253-264

Sharma D, Kanneganti TD (2016) The cell biology of inflammasomes: Mechanisms of inflammasome activation and regulation. J Cell Biol 213:617-629

Sharma G, Valenta DT, Altman Y et al (2010) Polymer particle shape independently influences binding and internalization by macrophages. J Control Release 147:408-412

Shen HM, Zhang Z, Zhang QF, Ong CN (2001) Reactive oxygen species and caspase activation mediate silica-induced apoptosis in alveolar macrophages. Am J Physiol Lung Cell Mol Physiol 280:L10-L17

Tenzer S, Docter D, Kuharev J et al (2013) Rapid formation of plasma protein corona critically affects nanoparticle pathophysiology. Nat Nanotechnol 8(10):772-781

Theus SA, Cave MD, Eisenach KD (2004) Activated THP-1 cells: an attractive model for the assessment of intracellular growth rates of mycobacterium tuberculosis isolates. Infect Immun 72:1169-1173

Thibodeau MS, Giardina C, Knecht DA et al (2004) Silica-induced apoptosis in mouse alveolar macrophages is initiated by lysosomal enzyme activity. Toxicol Sci 80:34-48
Tsuchiya S, Gota Y, Okumura H et al (1982) Induction of maturation in cultured human monocytic leukemia cells by a phorbol diester. Cancer Res 42:1530-1536

Tsuchiya S, Yamabe M, Yamaguchi Y et al (1980) Establishment and characterization of a human acute monocytic leukemia cell line (THP-1). Int J cancer 26:171-176

Turci F, Ghibaudi E, Colonna M et al (2010) An integrated approach to the study of the interaction between proteins and nanoparticles. Langmuir 26:8336-8346

Turci F, Pavan C, Leinardi R et al (2016) Revisiting the paradigm of silica pathogenicity with synthetic quartz crystals: the role of crystallinity and surface disorder. Part Fibre Toxicol 13:32

Vallyathan V, Shi XL, Dalal NS et al (1988) Generation of free radicals from freshly fractured silica dust. Potential role in acute silicainduced lung injury. Am Rev Respir Dis 138:1213-1219

Wang F, Salvati A, Boya P (2018) Lysosome-dependent cell death and deregulated autophagy induced by amine-modified polystyrene nanoparticles. Open Biol 8(4):170271

Wang F, Yu L, Monopoli MP et al (2013) The biomolecular corona is retained during nanoparticle uptake and protects the cells from the damage induced by cationic nanoparticles until degraded in the lysosomes. Nanomedicine 9:1159-1168

Warheit DB, Webb TR, Colvin VL et al (2007) Pulmonary bioassay studies with nanoscale and fine-quartz particles in rats: toxicity is not dependent upon particle size but on surface characteristics. Toxicol Sci 95:270-280

Wiessner JH, Mandel NS, Sohnle PG, Mandel GS (1989) Effect of particle size on quartz-induced hemolysis and on lung inflammation and fibrosis. Exp Lung Res 15:801-812

Wottrich R, Diabaté S, Krug HF (2004) Biological effects of ultrafine model particles in human macrophages and epithelial cells in mono- and co-culture. Int J Hyg Environ Health 207:353-361

Zhao Y, Sun X, Zhang G et al (2011) Interaction of mesoporous silica nanoparticles with human red blood cell membranes: size and surface effects. ACS Nano 5:1366-1375

Ziemann C, Escrig A, Bonvicini G et al (2017) Organosilane-based coating of quartz species from the traditional ceramics industry: evidence of hazard reduction using in vitro and in vivo tests. Ann Work Expo Heal 61:468-480

Publisher's Note Springer Nature remains neutral with regard to jurisdictional claims in published maps and institutional affiliations. 